\title{
Huey, Lacour, Murray, Neaton, and Visoly-Fisher to chair 2019 MRS Fall Meeting
}

\author{
www.mrs.org/fall2019
}

$\mathrm{T}^{\mathrm{s}}$ he Meeting chairs for the 2019 Materials Research Society (MRS) Fall Meeting are Bryan D. Huey (University of Connecticut, USA), Stéphanie P. Lacour (École Polytechnique Fédérale de Lausanne, Switzerland), Conal E. Murray (IBMT.J. Watson Research Center, USA), Jeffrey B. Neaton (University of California, Berkeley, and Lawrence Berkeley National Laboratory, USA), and Iris Visoly-Fisher (Ben-Gurion University of the Negev, Israel). The Meeting will be held December 1-6, 2019, in Boston, Mass.

Bryan D. Huey is a professor and the head of the Department of Materials Science and Engineering at the University of Connecticut (UConn). He earned a BS degree from Stanford University, MS and

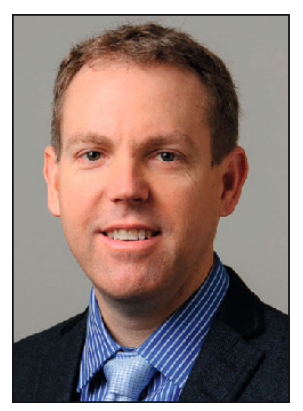

$\mathrm{PhD}$ degrees from the University of Pennsylvania, and worked as a postdoc at Oxford Materials and the National Institute of Standards and Technology before joining UConn in 2004. He is an expert in the development and application of advanced variations of atomic force microscopy (AFM). Using conventional, functional, high speed, and lately tomographic AFM, HueyAFM Labs investigates piezo-electrics, multiferroics, photovoltaics, semiconductors, microelectromechanical systems, biological cells and tissue, and pharmaceutical coatings. He received the Fulrath Award from The American Ceramic Society in 2016, and was honored as an Outstanding Faculty Member in UConn's Department of Materials Science and Engineering. Huey has co-chaired two MRS symposia, co-organ-ized Electronic Materials and Applications and US-Japan conferences, and served as the chair of the Basic Science Division of The American Ceramic Society.
Stéphanie P. Lacour holds the Bertarelli Foundation Chair in Neuroprosthetic Technology in the School of Engineering and is the head of the Laboratory for Soft Bioelectronic Interfaces at the École Polytechnique Fédérale de Lausanne

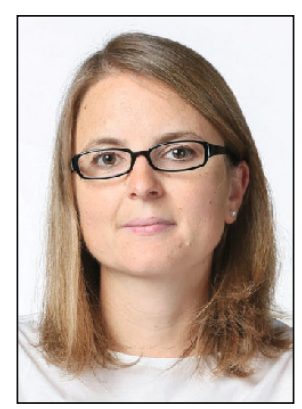

(EPFL). She is also a full professor in microengineering and bioengineering at EPFL. She is a co-founding member and the current director of the EPFL Center for Neuroprosthetics. Lacour received her $\mathrm{PhD}$ degree in electrical engineering from the Institut National des Sciences Appliquées de Lyon, France, and completed postdoctoral research at Princeton University and the University of Cambridge. Her work seeks to advance fundamental concepts in human-made electronic systems applied to biology. Specifically, the focus is on designing and manufacturing electronic devices with mechanical properties close to those of the host biological tissue so that long-term reliability and minimal perturbation are induced in vivo, and truly wearable systems become possible. Lacour was elected as a 2015 Young Global Leader by the World Economic Forum.

Conal E. Murray is a research staff member at the IBM T.J. Watson Research Center. He received a $\mathrm{ScB}$ degree in mechanics and materials science from Har-

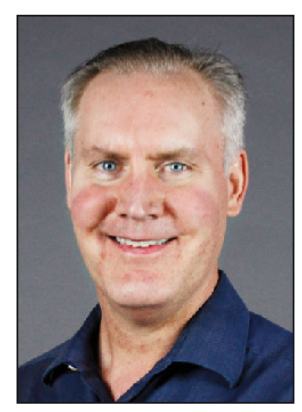
vard University, a MS degree in mechanical engineering from Boston University, and a $\mathrm{PhD}$ degree in materials science and engineering from Northwestern University. He joined the IBM T.J. Watson
Research Center in 2000. His work focuses on the micromechanics of semiconductor devices and the study of loss mechanisms in quantum computing. He is involved with the materials analysis project/group and the science and technology project/ group. He has received four IBM Research Division awards and an Outstanding Symposium Paper Award at the 2009 MRS Spring Meeting. He has authored or coauthored more than 100 scientific publications and three book chapters, and holds more than 70 patents. Since 2012, Murray has served on the organizing committee of the Denver X-ray Conference and has chaired several symposia on diffraction and residual stress.

Jeffrey B. Neaton is a professor of physics at the University of California, Berkeley (UC Berkeley), where his research interests include developing and applying theories and novel computational methods to predict, understand, and control phase behavior and electronic phenomena in complex materials from

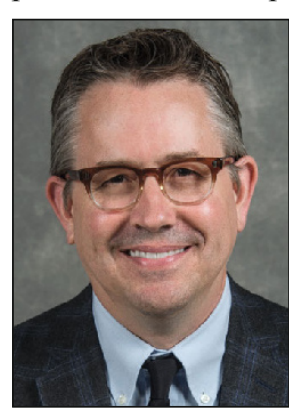
first principles. He serves as the Associate Laboratory Director for Energy Sciences at Lawrence Berkeley National Laboratory (LBNL), overseeing the Chemical Sciences and Materials Sciences Divisions, as well as the lab's two national scientific user facilities, the Advanced Light Source and the Molecular Foundry. He is also a senior faculty scientist at LBNL, the associate director of the Center for Computational Study of Excited-State Phenomena in Energy Materials at LBNL, and a member of the Kavli Energy NanoScience Institute at UC Berkeley. He received his $\mathrm{PhD}$ degree in physics from Cornell University and was a postdoctoral fellow at Rutgers, The State University of New 
Jersey. After working as a postdoc and staff scientist at the Molecular Foundry, he became director of the Molecular Foundry in 2013. Neaton is the recipient of a US Department of Energy Presidential Early Career Award for Scientists and Engineers, and is a Fellow of the American Physical Society.

Iris Visoly-Fisher is a senior lecturer with the Department of Solar Energy and Environmental Physics at the Swiss Institute for Dryland Environmental and Energy Research and the Blaustein Institute for Desert Research at Ben-Gurion Univer- sity of the Negev, Israel. She received her $\mathrm{BSc}$ and MSc degrees in materials engineering and a BA degree in physics from

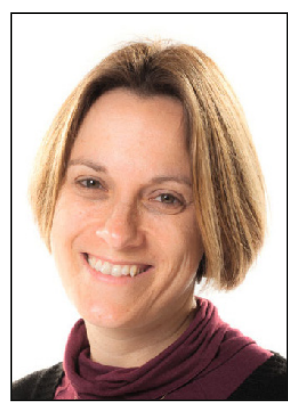

the TechnionIsrael Institute of Technology. She completed her $\mathrm{PhD}$ degree in materials and interfaces at the Weizmann Institute of Science in 2004, studying single grain boundaries in polycrystalline
CdTe solar cells. She was a postdoctoral fellow at Arizona State University, where she studied electrochemical potentialdependent current transport in single biomolecules. She joined Ben-Gurion University of the Negev as an assistant professor in 2008. Her current research interests include materials for solar-energy conversion and storage, optoelectronics, and surface science. She is an executive committee member of the Israel Vacuum Society, an editorial board member of the journal Scientific Reports, and a MRS member since 2000

\section{PREVIEW: XXVII International Materials Research Congress 2018}

August 19-24, Cancún, Mexico • www.mrs.org/imrc-2018

$\mathrm{T}_{\mathrm{s}}^{\mathrm{h}}$ Materials Research Society (MRS) and the Sociedad Mexicana de Materiales (SMM) are excited to be working together to host the International Materials Research Congress (IMRC) held annually in Cancun, Mexico. The 27th IMRC will be held August 19-24, 2018. The Meeting chairs are Hans M. Christen, Oak Ridge National Laboratory (USA); Coray M. Colina, University of Florida (USA); Ciro Falcony, Centro de Investigación y de Estudios del Instituto Politécnico Nacional (Mexico); and Cecilia Noguez, Universidad Nacional Autónoma de México (Mexico).

The Congress will feature 38 symposia covering nanomaterials and 2D materials; hybrid materials, bioinspired materials, and soft matter; materials for energy conversion, storage, and harvesting; development of new characterization, modeling, data analytics, and design methods; structural materials and metallurgy; and a general cluster on a variety of topics.

Everyone registered for the meeting may take part in the fourth NANOMXCN: Mexico-China Workshop on "Nanomaterials, Science, Technology: Renewable Energy and Environment Remediation." The project aims to promote collaboration between Mexico and China, including the Hong Kong Special Administrative Region (SAR), with the support of colleagues worldwide. The workshop will focus on the use of nanostructured materials to address issues in modern day society in the fields of renewable energy and environmental remediation, and will include short sessions to exchange ideas for the design of specific actions to prepare dynamic collaborations. The meeting will also include an "Advanced Defense Materials" workshop, which will focus on the design, synthesis, integration, and application of novel materials/processes to address defense application needs.

Several tutorials will be offered to complement the symposium sessions, including Computational DFT Methods for Catalytic Materials; Design of Advanced Steels and Advanced Coating for Steels; Electron Crystallography in TEM: Orientation Imaging to Strain and Metals to Archaeology at $\mathrm{nm}$ Scale; Hybrid Perovskite Solar Cells: Fundamentals to Cell Fabrication and Scale-Up; Mentoring Young Scientists: Developing Survival Skills; Probing Nanomaterials in Space or Time with High Spatial and Energy Resolution; and Texture and Microstructure Analysis Using Electron Backscatter Diffraction.
Plenary speakers at this year's event are Susan Trolier-McKinstry, The Pennsylvania State University, USA; Yuichi Ikuhara, The University of Tokyo, Japan; Amanda S. Barnard, CSIRO, Australia; Ben L. Feringa, University of Groningen, The Netherlands; and Galo Soler Illia, Universidad Nacional de San Martín, Argentina. Leonardo Beltrán Rodriguez, Deputy Secretary for Planning and Energy Transition, Mexico, will present the Science, Technology, and Society Lecture.

To promote postgraduate degrees in materials science and engineering and related areas, the Mexican Society of Materials will organize an exhibition with the IMRC. There will also be an exhibit of instruments, products, and services in the field of materials science and related topics, with participation by worldrenowned companies.

This annual meeting provides an exciting multidisciplinary stage to present new directions in materials research and technology, as well as opportunities to exchange ideas with some of the foremost experts in the field. IMRC has become a leading conference with approximately 1700 attendees from more than 50 countries.

For more information, visit www.mrs. org/imrc-2018. 